\title{
Do evidence networks make a difference?
}

Ruth Stewart

Published by Journal of Development Effectiveness

\begin{abstract}
As part of the Global Evidence Summit in Cape Town in September 2017, Prof Ruth Stewart gave the keynote addressing the question of 'Do evidence networks make a difference?' The following text is based closely on that opening address. She outlines how evidence networks make a difference by building our shared understanding across the evidence ecosystem, enable growth in our shared capacities, and enable a potential and readiness for change. In this paper she provides additional information supporting each of these three ways in which evidence networks make a difference, as well as elaborating on how her work, and that of her Centre at the University of Johannesburg, is closely aligned with the production and use of evidence synthesis. She makes a strong case for her central argument: 'If you want to go fast, go alone. If you want to go far, go together.'
\end{abstract}

Keywords: networks, evidence, Global Evidence Summit 


\section{Do evidence networks make a difference? Opening address at the Global Evidence}

\section{Summit}

Do evidence networks make a difference? I believe two key mechanisms have the power to improve decision-making and reduce poverty and inequality in our continent: one is relatively new - evidence maps and evidence synthesis and all that; and one is as old as the hills - relationships, specifically networks. See Table 1 for a brief history of our work producing evidence maps and syntheses, and on ensuring that this evidence is both useful and used.

\section{Insert Table 1 here}

Most of my readers already know more about evidence synthesis than I do, so I am writing about networks, specifically evidence networks. I'm focusing on why networks are important and whether evidence networks make a difference. As the chairperson of the Africa Evidence Network I draw on experiences within our own network and the many other evidence networks across Africa and further afield.

I start with an assumption that our shared goal is that through the production and use of high quality evidence we want to make a difference to the enormous challenges in our world. I cannot underline this enough: our goal is to make a difference. My argument is that evidence networks play a key role in our ability to make that difference. This is in line with Rick Davies's argument for network perspectives to evaluate development interventions (Davies 2003), in which he makes a case for the importance of networks and consideration of networking when assessing objectives and impacts. 
Together we make up many parts of what is increasingly described as an evidence ecosystem (Davies, 2003). Some of us collect data, some of us teach, some of us analyse, some of us write, some of us read, many of us negotiate, others interpret, others make use. We are part of a larger whole. When we work in isolation or in silos, we risk blockages in the smooth running of our ecosystem. When we share information, engage, get to know one another, collaborate we are forming what you might call 'evidence networks' within the evidence ecosystem. Some networks are sector specific, such as WHO's health-focused EVIPNet [www.who.int/evidence/], some focus on particular health areas, such as Share-Net International which covers sexual and reproductive health [http://share-netinternational.org]. Others are regional (what Keck and Sikkink (1998) call 'transnational networks'. Others focus on particular methodologies.

So what is it about networks that make all the difference? Ramalingham (2011) explores a similar question from a theoretical perspective, asking how networks are theoretically different and what this means for what they can achieve. He highlights roles, deliverables and transactions within the network value framework as a means to assess how networks make a difference. Here I draw on our experience over the last 5 years, and all that I have read and heard about networks. In doing so I have identified three things: better understanding, increased capacity, and greater potential for change.

\section{Building better understanding}

I start by exploring how and why they build better understanding. Supporting data and analyses from the Africa Evidence Network [www.africaevidencenetwork.org] are provided in Table 2. 
I understand that the majority of people reading this are researchers, and that most of you are based in, or affiliated with, universities around the world. What an amazing wealth of knowledge and experience. I want to tell you that if you want to make a difference, you need more than an understanding of your own field of research, even more than understanding systematic review methodology. To make a difference you need a better understanding of who else is part of the evidence ecosystem in which you work, what their work is about, their priorities and processes (Keck and Sikkind,1998).

We also hope that this will be read by members of NGOs, governments, intergovernmental agencies, charities, and more; practitioners and decision-makers. People who, we believe, sift through our systematic reviews, evidence maps and other research and, we hope, make better decisions as a result. Decision-makers, are often the 'target of researchers, who want decision-makers to read their research but do little very little to understand the contexts priorities or processes in which decision-makers work. If evidence-informed decision-making is about bringing evidence and decisions closer together, then maybe we should start with a shared understanding of the various processes, priorities and potentials in one another's work. Evidence networks enable better understanding and it is through better understanding of one another and where we fit in a bigger picture that we can make a difference. Understanding builds trust (Church et al. 2003) and trust is essential for networks to be effective.

Members of the Africa Evidence Network have told us that being part of an evidence network can help bring people together to learn from one another and build a 'critical mass' of scientists, knowledge brokers and decision-makers.

I was born and grew up in Malawi, one of the poorest countries in the world. I live and work in South Africa, one of the most unequal countries in the world. I want to 
make a difference. I cannot do it on my own, however good a researcher I am, even if I am the most talented of decision-makers, the best knowledge broker, the most discerning funder. I need networks. Networks like the Cochrane Africa Network [http://africa.cochrane.org], which is focusing on ensuring that by better understanding the problems faced across the continent, we produce better systematic reviews to meet evidence needs. Networks like the WHO's Evidence-informed policy network (EVIPNet), which operates in a number of regions, including Africa, and focuses on forging relationships and building mutual respect to facilitate evidence use, all based on shared understanding of evidence and how it can be useful. Their success stories include: enabling greater consideration of evidence in Uganda's national health plan; integration of evidence into Cameroon's malaria prevention plan; shaping alcohol policies in the Republic of Moldova; and, reducing perinatal mortality in Brazil (WHO 2016).

Do evidence networks make a difference? They do, by helping us to better understand each other, and that includes a better understanding of decision-makers and decision-making, of policy processes, of political and economic histories. Evidence networks enable this greater understanding of those other elements within our evidence ecosystems that we do not yet know about. Cummings and colleagues (2003) call this enabling of greater understanding by networks 'structural opportunity to share'.

\section{Increasing our capacity}

Next I turn to the challenge of increasing our capacity. It is hard for me to admit that I do not know it all, do not have all the answers and, despite what I tell my husband, I am not always right. But I have learnt that I don't only have something to share, but also much to learn, and that sticking with people 'just like me' limits what I can learn. 
I spent much of the last four years running a wide variety of workshops for decision-makers across southern Africa. The idea was to build the capacity of decisionmakers to use research evidence. Actually my team and I learnt far more from the public servants that we met, than we could ever have imagined. Hearn and Mendizabal (2011) refer to this potential for shared learning within networks in terms of their ability to 'convene' events and build social capital, enabling 'resource mobilisation': something that has the potential to increase the capacity and effectiveness of members, enabling knowledge creation and innovation.

We need evidence networks and the broader relationships that they bring to enable us to learn from one another so that together we can make a difference (Cummings et al, 2003). Our experience is in keeping with many other instances of change through shared learning (Stone and Maxwell, 2004). Data and analyses from the Africa Evidence Network illustrating this finding are reported in Table 3.

If you take a few examples of the production and use of evidence that are really making a difference, in each case, those involved made concerted efforts to learn from one another, and in each case their relationships began in the form of evidence networks, whether formal or informal. The McMaster Forum model [www.mcmasterforum.org] is based on shared learning and respect. By learning from one another, health decision-makers and researchers have been able to develop a system that provides the best available evidence in a timely manner for decision-making. In this case the relationships and networks that they have established have enabled both the production of more useful evidence and its use. Closer to home, we have seen how a willingness for different stakeholders to share their capacity and learn from one another has led to the development of a methodology for evidence mapping that, whilst still in its pilot phase, has made a direct impact on policy discussions. This has been based on a 
co-production model between the national Department for Planning, Monitoring and Evaluation, and a number of partners, including my own research Centre [www.africacentreforevidence.org]. Cummings and van Zee (2005) highlight how communities of practice, such as this evidence mapping community, are in fact types of networks. In line with Hearn and Mendizabal (2011), again, through sharing capacity, we have seen the production of more useful evidence.

\section{Insert Table 3 here}

Members of the Africa Evidence Network have told us that they learn from those in other sectors, and that by getting to know one another "now we work together and use evidence to inform policy". Our members they also learn from others in the same sector with different experience. They have told us how individuals have 'become a mentor': "he has become my mentor and it has helped me". And sometimes just having others to draw on helps build capacity: 'It 'beefs' me up ... It ties me into something bigger". Do evidence networks make a difference? They do, by increasing our understanding, and by increasing our shared capacity.

\section{Building potential, readiness for change}

The quotes I've been using come from our survey of members. I'll be honest with you, it's not easy to capture instances of networks changing the world. Instead networks seem to make a difference by building greater potential for change. Some of you will have read Duncan Green's book 'How change happens' (Green 2016). In there he talks about what triggers change. If you read his book, you will sadly be forced to accept that change does not follow swiftly from the publication of our research papers, however high profile the journal might be, however long the words we use. Instead 
change is often triggered by a catastrophe, a change in leadership, a financial windfall or recession, a public outcry, a hurricane, a drought. What Duncan identifies as key is to be ready for when these triggers occur. This is something that the various global evidence synthesis organisations aim to do with regards the production of systematic reviews of the evidence base on a wide range of issues. Through the production of these thorough overviews, the organisations, and the authors of reviews, aim to be 'ready' with the evidence when opportunities for use arise (Langer and Stewart 2014; Stewart 2014).

Key to this paper is that we have found that evidence networks can build this state of readiness. Data and analyses underlying this finding are reported in Table 4. Understanding evidence ecosystems, understanding where we fit, who else is in the system, what they do, what they need, and how decisions are made: all of this means that we can be ready. This can include being ready when that funding call comes up having a partner in mind, a collaborator we trust, someone whose advice we can ask, a community we can call on (Cummings \& van Zee, 2005). It can include being ready when a need for evidence arises, so decision-makers know whose advice to seek. It can mean having a network so that together we can act when we see opportunities for change. Evidence networks provide potential, readiness, and in doing so, they are the foundations that one day can lead to change. People tell us "I knew who to call". "We trusted each other so when the call came we could act". 


\section{Concluding comments}

Do evidence networks make a difference? Yes. Networks share information increasing our collective understanding. Networks enable sharing of capacity. Networks build potential, readiness for change.

The Africa Evidence Network started in 2012 with 23 disparate and very different people from across Africa making a commitment to one another to stay in touch, to share information and to learn from one another. See Table 5 for more information on the history and sustainability of the Africa Evidence Network. Since then we have grown to over 1200 people from nearly 40 countries. Twenty-six percent of our members are from governments across Africa. We share information about the evidence ecosystems across the continent, what is happening where, workshops, new publications, seminars, webinars, training, funding and more. We liaise with other evidence networks. We have a website, blogs, newsletters, we tweet, we share, we meet. If you want to know more about us and the many evidence networks here today, get in touch. Networks are inherently keen to hear from you. If you'd like to get to know the African evidence community better, come to Evidence 2018 in Pretoria in September 2018.

Those of you who have flown out through OR Tambo Airport will see in the international departure lounge the mural that says: "If you want to go fast, go alone. If you want to go far, go together.” Do evidence networks make a difference? You, me, the Summit: we are the answer. 


\section{References}

Africa Evidence Network. 2016a. Africa Evidence Network survey report [online].

Johannesburg: UJ-BCURE, University of Johannesburg, South Africa. Available from: http://www.africaevidencenetwork.org/wp-content/uploads/2014/06/AENSurvey-Report.pdf [Accessed 30 Oct 2017].

Africa Evidence Network. 2016. Africa Evidence Network testimonials report [online]. Johannesburg: UJ-BCURE, University of Johannesburg, South Africa. Available from: http://www.africaevidencenetwork.org/wp-content/uploads/2014/06/AENsust_testimonials_161024.pdf [Accessed 30 Oct 2017].

Church, M., Bitel, M., Armstrong, K., Fernando, P., Gould, H., Joss, S., MarwahaDiedrich, M., de la Torre, A.L. and Vouhé, C., 2003. Participation, relationships and dynamic change: new thinking on evaluating the work of international networks, Working Paper 121 London: Development Planning Unit, UCL

Cummings, S. and van Zee, A., 2005. Communities of practice and networks: reviewing two perspectives on social learning KM4D Journal 1(1), 8-22.

Davies, R., 2003. Network perspectives in the evaluation of development interventions: more than a metaphor, paper delivered at EDAIS Conference November 24-25, 2003, New Directions in Impact Assessment for Development: Methods and Practice.

Dayal, H. and Langer, L. 2016 Policy-relevant evidence maps: A departmental Guidance Note. Pretoria: Department of Planning, Monitoring and Evaluation:, South Africa.

Green, G., 2016. How Change Happens Oxford: Oxford University Press. ISBN-10: 0198785399

Hearn, S. and Mendizabal, E., 2011. Not everything that connects is a network, ODI Background Note, May 2011 London: ODI

Keck, M. and Sikkink, K., 1998. Activists beyond borders: advocacy networks in international politics Ithaca: Cornell University Press

Korth, M., Stewart, R., Langer, L., Madinga, N., Rebelo Da Silva, N., Zaranyika, H., and van Rooyen, C. 2014. What are the impacts of urban agriculture programs on food security in low and middle income countries? A systematic review. Environmental Evidence. 3(21), 1-10. Available from: 
http://www.environmentalevidencejournal.org/content/3/1/21 [Accessed 30 Oct 2017]

Langer, L. 2015. When will we ever learn? - An evidence gap map and synthesis of the effectiveness of sport-for-development interventions in Africa, African Journal for Physical, Health Education, Recreation and Dance, March 2015 supplement, 195-208.

Langer, L., and Stewart, R. 2014. What have we learned from the application of systematic review methodology in international development? - A thematic overview. Journal of Development Effectiveness 6(3): 236-248. DOI: 10.1080/19439342.2014.919013 Available from: http://www.tandfonline.com/doi/abs/10.1080/19439342.2014.919013\#.VKgfylvl fzI [Accessed 30 Oct 2017]

Langer, L., Erasmus, Y., Tannous, N., and Stewart, R. 2017. How stakeholder engagement has led us to reconsider definitions of rigour in systematic reviews. Environmental Evidence. 6(20) DOI 10.1186/s13750-017-0098-7

Ramalingham, B., 2011. Mind the network gaps. London: ODI

Stewart, R., van Rooyen, C., Dickson, K., Majoro, M., and de Wet, T. 2010. What is the impact of microfinance on poor people? A systematic review of evidence from sub-Saharan Africa. Technical report. London: EPPI-Centre, Social Science Research Unit, University of London. ISBN: 978-1-907345-04-3. p1-104

Stewart, R., van Rooyen, C., Korth, M., Chereni, A., Rebelo Da Silva, N., and de Wet, T. 2012 Do micro-credit, micro-savings and micro-leasing serve as effective financial inclusion interventions enabling poor people, and especially women, to engage in meaningful economic opportunities in Lower and Middle Income Countries?' Technical Report. London: EPPI-Centre, Social Science Research Unit, Institute of Education, University of London. 1-187.

Stewart, R. and Oliver, S. 2012 Making a difference with systematic reviews. In Gough, D., Oliver, S., and Thomas, J. Eds. An introduction to systematic reviews. London: Sage 227-244

Stewart, R. 2014. Changing the world one systematic review at a time: a new methodology for making a difference. Development Southern Africa. 31:4, 581590.

Stewart, R., Erasmus, Y., Zaranyika, H., Rebelo Da Silva, N., Korth, M., Langer, L., Madinga, N., Randall, N., and de Wet, T. 2014 The size and nature of the 
evidence base for smallholder farming in Africa: a systematic map. Journal of Development Effectiveness, 6 (1): 58-68. DOI:10.1080/19439342.2013.877060

Stewart, R., Erasmus, Y., and the UJ-BCURE team. 2017a. Working for solutions: a problem-based and relationship-centred approach to building capacity to use research evidence in Africa [online]. Johannesburg: Africa Centre for Evidence. Available from: https://africacentreforevidence.org/wpcontent/uploads/2017/10/Working-for-solutions-in-Africa_UJ_BCURE-20142016-Report.pdf [Accessed 30 Oct 2017].

Stewart, R., Nduku, P., Langer, L. 2017b. Capacity in Africa: The results of a survey on support for and production of evidence maps and evidence syntheses, including systematic reviews [online]. Johannesburg: Africa Centre for Evidence as secretariat to the Africa Evidence Network, University of Johannesburg. Available from: http://www.africaevidencenetwork.org/wpcontent/uploads/2014/06/Africa-Evidence-Network-Capacity-in-Africa-SurveyReport-2017.pdf [Accessed 30 Oct 2017].

Stone, D. and Maxwell, S., Eds. 2004. Global knowledge networks and international development: bridges across boundaries. Abingdon: Routledge

van Rooyen, C., Stewart, R., and de Wet, T. 2012. The impact of microfinance in subSaharan Africa: A systematic review of the evidence. World Development. 40(11): 2249-2262. DOI:10.1016/j.worlddev.2012.03.012.

van Rooyen, C., Stewart, R., de Wet, T. 2013. Systematic review methodology for development: An example from microfinance. Africanus: Journal of Development Studies. 43(1): 65-77.

WHO. 2016. EVIPNet in action: 10 years, 10 stories. Geneva: WHO 
Table 1: The on-going work of the Africa Centre for Evidence towards the production and use of evidence syntheses and evidence maps

Whilst the Africa Evidence Network uses a broad interpretation of evidence, including a wide range of stakeholders interested in the production and use of evidence for decision-making, the Network's secretariat a the Africa Centre for Evidence, is more specifically aligned with evidence maps and systematic reviews.

In all, our team at the University of Johannesburg have produced over 25 evidence maps and systematic reviews to date. These have ranged from maps and reviews on microcredit (Stewart et al. 2015; 2012; van Rooyen et al. 2012; 2014), to urban agriculture (Korth et al. 2014) and small-holder farming (Stewart et al. 2014), sports for development (Langer 2015), women in wage labour (Langer et al. in press), human settlements (Dayal and Langer 2016), and many more. We work closely with many of the large global evidence synthesis organisations, including Cochrane, the Campbell Collaboration, the Collaboration for Environmental Evidence, UCL's EPPICentre, and 3ie. We provide capacity-building across the continent for research teams wanting to produce maps and reviews, with courses offered in 2017 in Uganda, Ghana and South Africa. We believe strongly in collaboration and work with a range of partners from around the world, including colleagues in Australia, Canada, the USA, Sweden, France, the UK, and more local centres across Africa, in particular the Africa Centre for Systematic Reviews and Knowledge Translation at Makerere University in Uganda, the Centre for Evidence-Based Health Care at the University of Stellenbosch in South Africa, and the South African Cochrane Centre.

Furthermore we also support evidence use by decision-makers. This has included providing direct support to the governments of Malawi and South Africa 
through the University of Johannesburg-led programme to Build Capacity to Use Research Evidence (UJ-BCURE) (Stewart et al. 2017a). All of our maps and reviews are guided by international, multi-disciplinary and cross-sector advisory groups (Oliver and Stewart 2012;Langer et al. 2017). As with our Network activities, we are committed to ensuring that through relationships and networks we increase both the usefulness and use of the research we produce (Stewart et al, 2017a). 
Table 2. Networks build understanding: Findings from the Africa Evidence Network

Members use the Africa Evidence Network to enquire about others' work, and to share their own experiences. We average 30 emails monthly with enquiries or requests to share information across the Network, and we share an average of 25 stories, events or publications with our members via our website and newsletter each month. Through bimonthly blogs, our members volunteer to tell their stories and showcase their experiences.

Members from across Africa access the Network website to access information about work across the continent. Since July 2017 we have averaged 8000 visitors and over 70,000 hits on our website each month.

The most cited benefit of our events in particular our biennial conference, (as reported in our surveys and via event feedback forms), is the opportunity to meet with individuals from other fields and sectors and to understand more about their work.

In our annual survey our members have reported the benefits of hearing about other peoples' work. A colleague from Zimbabwe reported this opportunity for learning as follows:

[At the AEN conference] we interacted with a lot of experts and organisations and I learned quite a lot about what others are doing to promote EIDM. As an organisation we have also managed to grow. And learn what other people are doing in their various capacities, both regionally and internationally. I have been able to access resources that I was not previously aware of which has informed some of the research that I am doing. I got very good links through the AEN. Participating in the recent knowledge café was also great. (Africa Evidence Network 2016b) 
Table 3: Networks enable capacity-sharing: Findings from the Africa Evidence Network

The Network shares training opportunities: One of the three most often received enquiries by the Network relates to training, both asking about opportunities and sharing courses.

The Network has enabled individuals to gain exposure to the wider evidenceinformed decision-making community: A member recently wrote to us to share how the network enabled him to identify funding opportunities and secure a bursary to attend a key evidence conference. This was as a result of an initial response to his enquiry, and then via information reported in our newsletter.

Our annual surveys (Africa Evidence Network 2016a; 2017) have consistently highlighted the value of capacity-sharing opportunities provided via Network communications and called for more exposure to capacity-sharing.

The events provided by the Network deliberately seek to combine participants from across sectors and fields. This opportunity for capacity-sharing across traditional boundaries at our events is highlighted by members as particularly valuable. A government official in South Africa described this benefit in the following way:

It has also linked us to researchers to help us with integrating evidence. We have always worked very closely with researchers in the science sector, but the newsletter does highlight different programmes and approaches and it reminds us of the importance of research. What has been most useful has been [the] workshops they arranged that we also attended with the DPME about two years ago. And last year there was a workshop where Phil Davies spoke which was very useful... The events and platforms have facilitated active engagements and opportunities for learning, so they have been useful. 
Table 4: Networks create greater readiness for change: Findings from the Africa Evidence Network

Whilst we have found it particularly challenging to capture stories of change from our Network, we have anecdotal accounts of the difference we make, many of which speak to the idea that there is greater readiness for change as a result of being part of the Network. The following examples are consistent with the feedback we receive, both through our annual survey and on an ad hoc basis.

We have captured three specific instances of colleagues meeting via the Network and then applying together for funding. This included a partnership between a South African University and a Ugandan University, a partnership between a Zimbabwean think tank and a Malawian medical school, and an emerging collaboration between those working on evidence-informed decision-making for environmental management across the continent that include participants from across Africa and beyond.

A network analysis of our members (Africa Evidence Network 2016a) indicates a baseline amongst respondents prior to their membership of 173 individuals with 298 cross-linkages (or ties). However, at end-line, after being able to interact through the AEN, 240 individuals reported connecting with one another resulting in a total of 535 cross-linkages — a strong growth in interaction and relationships enabled by the Network. What is more is that the AEN was highly successful in clustering and bundling interactions: that is, the Network succeeded in forming a hub for interactions and provided a central reference point for the EIDM community of practice in Africa.

Colleagues across the Network have shared accounts of the difference the Network has made (Africa Evidence Network 2016b). Examples include a government official from Malawi who wrote: 
I have used [the AEN] when I was doing my graduate degree in Australia. I used it to share ideas with [my] colleagues in Malawi. I am currently setting up the quality control department in the Ministry of Health, so one area [that I also use the AEN] is [in] making sure that we use evidence, and being linked up to [the AEN] Twitter and website has been very valuable to me. It has shown me ideas and areas for improvement, especially on systematic reviews.

\section{Another member wrote:}

The focus on the use of evidence when we make decisions has become part of my thinking. I joined the network nine months ago, and now I tell my manager that everything we do and every decision we make must be based on evidence and specifically on research evidence. Where I was at that point, it was actually me, going to a meeting at a district level, and then coming from there, going to my workplace and me talking to the people at my workplace, it was me participating in the meeting and going back to my boss.

Another colleague from Zimbabwe shared how being part of the Network has increased their organisations credibility: "Being part of AEN also brings credibility to our organisation and helps us to attract more high level participants to our events." (Africa Evidence Network 2016b) 
Table 5. The history of the Africa Evidence Network

The Africa Evidence Network and its secretariat at the Africa Centre for Evidence are closely tied to the production and use of evidence syntheses and evidence maps. Whilst the Network focuses on all forms of evidence, their production and use, its history dates back to a joint 3ie and Campbell Collaboration minicolloquium in Dhaka, Bangladesh in late 2012, where our team gave presentations and training on systematic reviews. The 23 African delegates at this Asian meeting, got together over dinner and committed to keeping in touch: hence the Africa Evidence Network was born.

The Network operated on volunteer time during 2013 until we were able to secure a large DFID grant to support evidence use for 2014-16. This included building and sustaining the AEN. Under DFID support the Network grew to over 1000 people, sharing regular news updates, hosting biennial conferences, and with an established secretariat at the University of Johannesburg. At the end of 2016, we returned to a volunteer-led phase, with the Chairperson, Ruth Stewart, sponsoring the network coordinator from her own research funds. The importance of the role of the Network, however, spoke for itself, and attracted funding from the William and Flora Hewlett Foundation, who have committed 19 months of funding for the Network from September 2017. With or without funding, the Network relies on the active participation of its many members across Africa and further afield. 